\title{
DÜBLIN
}

Technological University Dublin

ARROW@TU Dublin

1994

\section{Dielectric Response of Ferroelectric Liquid Crystal Cells}

\author{
Yuri Panarin \\ Technological University Dublin, yuri.panarin@tudublin.ie \\ Huan Xu \\ Trinity College Dublin, Ireland \\ seamus Mac Lughadha \\ Trinity College Dublin, Ireland
}

See next page for additional authors

Follow this and additional works at: https://arrow.tudublin.ie/engscheleart2

Part of the Physics Commons

\section{Recommended Citation}

Panarin, Y. et al. (1994) Dielectric Response of Ferroelectric Liquid Crystal Cells, Journal of Applied Physics, vol.33 (1994) pp.2648-2650

This Article is brought to you for free and open access by the School of Electrical and Electronic Engineering at ARROW@TU Dublin. It has been accepted for inclusion in Articles by an authorized administrator of ARROW@TU Dublin. For more information, please contact arrow.admin@tudublin.ie, aisling.coyne@tudublin.ie, gerard.connolly@tudublin.ie.

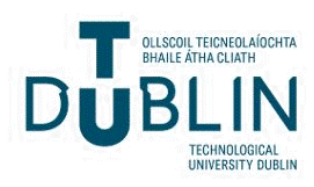


Authors

Yuri Panarin, Huan Xu, seamus Mac Lughadha, and Jagdish Vij

This article is available at ARROW@TU Dublin: https://arrow.tudublin.ie/engscheleart2/116 


\title{
Dielectric Response of Ferroelectric Liquid Crystal Cells
}

\author{
Yuri P. Panarin, Huan Xu, Seamus T. Mac Lughadha and Jagdish K. Vij* \\ Department of Microelectronics and Electrical Engineering, University of Dublin, Trinity College, Dublin 2, Ireland \\ (Received June 10, 1993; accepted for publication August 21, 1993)
}

The dielectric response of a number of homogeneously aligned FLC cells has been investigated. Several relaxation processes exhibiting behaviour with different relaxation times are found for the first time. These are identified with the structure of the smectic layers in the cell and the parameters of the FLC mixtures. The assignment of these processes is based on a combination of electro-optic and dielectric investigations.

KEYWORDS: ferroelectric liquid crystals, dielectric response, surface-stabilized cells

\section{Introduction}

The dielectric behaviour of ferroelectric liquid crystals (FLC) is known to be complex. In the high frequency $(\mathrm{GHz})$ range there exists the so called high frequency Goldstone and Soft modes. ${ }^{1,2)}$ These are mainly due to the molecular dynamics of the individual molecules. In the frequency range less than $1 \mathrm{MHz}$, several investigations ${ }^{3,4)}$ have yielded two relaxation modes in FLC's corresponding to the collective dynamics of the system. The fluctuation of the tilt angle $(\theta)$ gives rise to the Soft mode whereas the fluctuation of the azimuthal angle $(\varphi)$ gives to the Goldstone mode (frequency range $1 \mathrm{~Hz}-10 \mathrm{kHz}$ ). The present paper is concerned with the dielectric studies of the low-frequency Goldstone mode in FLC cells. The Goldstone mode is usually understood to be the fluctuation of the director around the helical axis. ${ }^{3,4)}$ Recent dielectric measurements ${ }^{5,6)}$ have shown the existence of at least two relaxation processes in surface stabilized FLC (SSFLC) cells where the helical structure is suppressed by the surface interactions. In this paper we attempt to identify and characterize the possible relaxation processes corresponding to the low frequency process.

\section{Experimental}

To prepare FLC cells with different smectic layer structures we use various FLC mixtures with different parameters. Sample cells consisted of ITO coated glass plates. The conducting inner surfaces were spin-coated with polyimide alignment layer and rubbed parallel. The cells were filled in the isotropic phase of the FLC mixture and then were cooled to the smectic $\mathrm{C}^{*}$ phase. Textures of the experimental cells were observed using a polarizing microscope. Dielectric measurements, in the frequency range $0.1 \mathrm{~Hz}$ to $1 \mathrm{MHz}$ were made using a Schlumberger 1255 frequency response analyser and a Chelsea dielectric interface. This system enabled us to apply direct voltage bias $(0-40 \mathrm{~V})$ and alternating voltage $\left(0-3 \mathrm{~V}_{\mathrm{rms}}\right)$ to the samples during measurements. The dielectric measurements were carried out on homogeneously aligned (planar) samples; therefore providing $\varepsilon_{\perp}$ and optical textures could be observed through a polarising microscope simultaneously. FLC parameters: the spontaneous polarization and the switching time were measured using the integral

*Author for correspondence. reversed current method..$^{7}$

\section{Results and Discussion}

The dielectric response of FLC cells depends strongly on the measuring voltage and the ratio of the helix pitch to the cell thickness. We prepare two different types of cells: helical cells $\left(p_{0} \ll 0.1 d\right)$, surface stabilized cells $\left(p_{0}>d\right)$ with suppressed helix. Where $p_{0}$ and $d$ are the helical pitch and cell thickness respectively.

\subsection{Dielectric response of FLC cells with short pitched mixture}

As mentioned above for $d>p_{0}$ the helical structure is present in the cell. The FLC parameters of the shortpitched mixture ZhKS-311 (NIOPIK) are $p_{0}=0.2 \mu \mathrm{m}$, $P_{\mathrm{s}}=110 \mathrm{nC} / \mathrm{cm}^{2}$. The dielectric response of the cell with a short pitched mixture can be described by the Havriliak-Negami equation: ${ }^{8)}$

$$
\varepsilon(\omega)=\varepsilon_{\infty}+\frac{\varepsilon_{\mathrm{s}}-\varepsilon_{\infty}}{\left[1+\left(i \omega \tau_{0}\right)^{(1-\alpha)]^{\beta}}\right.}
$$

where $\varepsilon(\omega)$ is the frequency dependent complex permittivity, $\tau_{0}$ is the step relaxation time, $\varepsilon_{\mathrm{s}}$ is the static dielectric constant and $\varepsilon_{\infty}$ is the high frequency permittivity. Using fitting programs on a computer these parameters are found to be $\Delta \varepsilon=\varepsilon_{\mathrm{s}}-\varepsilon_{\infty}=57, \alpha=0.07$, $\beta=1, \tau_{0}=0.1 \mathrm{~ms}$. These parameters show that the relaxation process is Debye like with an almost single relaxation time. These parameters are also found to be independent of the bias voltage up to $10 \mathrm{~V}$, the measuring voltage up to $3 \mathrm{~V}_{\mathrm{rms}}$ and the cell thickness. This relaxation process shown by the dielectric response of the helical cells is often called the Goldstone mode itself $^{3)}$ and deals with small distortion of the equilibrium helical structure through the rotation of the director along the helical axis at a constant tilt angle. The dynamics of the spontaneous polarisation vector $\boldsymbol{P}_{\mathrm{s}}$ obeys the equation ${ }^{3)}$

$$
\gamma_{\varphi} \sin \theta \frac{\partial \varphi}{\partial t}=K_{\varphi} \sin ^{2} \theta \frac{\partial^{2} \varphi}{\partial z^{2}}+P_{s} E(t) \sin (q z),
$$

where $\gamma_{\varphi}$ is the rotational viscosity, $K_{\varphi}$ is the mean elastic constant, $\theta$ : tilt angle, $\varphi$ : azimuthal angle, $q=2 \pi / p_{0}$ and $z$ is axis of the helix. This has been investigated both theoretically and experimentally in ref. 3 . We also note that the dielectric response of the short-helixpitch cell is the same before and after the cell is subjected to a low frequency high electric field. 


\subsection{Dielectric response of the SSFLC cells}

For preparing SSFLC cells we used SCE13, Merck with cell thicknesses $d$ varying from $2-40 \mu \mathrm{m}$. Pitch of the mixture is of the order of $10-15 \mu \mathrm{m}$ and $P_{\mathrm{s}}=27 \mathrm{nC} /$ $\mathrm{cm}^{2}$. Dielectric response of such cells may exhibit several modes and these modes may simultaneously be present in the cell. Using computer fitting programs, we can distinguish these processes with a superposition of the relaxation processes using eq. (1). Dielectric measurements show that the dielectric response of a SSFLC cell depends primarily on the measurement parameters (applied alternating voltage, bias voltage). Furthermore the dielectric response is different before and after the cell is subjected to a high electric field. Observation of the cell textures using a polarising microscope confirms that the chevron structure transforms to a striped bookshelf structure on the application of a strong electric field. The dielectric response of the cell with both structures is discussed below.

\subsubsection{Dielectric response of a SSFLC cell with chevron structure}

The dielectric loss $\left(\varepsilon^{\prime \prime}\right)$ spectrum for a SSFLC is shown in Fig. 1 for different measuring voltages. The parameters of the cell using SCE13 are: $d=7 \mu \mathrm{m}$, $V_{\text {bias }}=0 \mathrm{~V}, T=22^{\circ} \mathrm{C}$. This figure shows the presence of three relaxation processes under these conditions. Computer fitting of these results using eq. (1) provides us with information about the dependence of $\Delta \varepsilon^{(i)}$ and the relaxation frequency $1 / 2 \pi \tau^{(i)}$ on the applied voltage for these processes. As seen from Figs. 2(a) and 2(b) the number and the relative magnitude of these processes is strongly dependent on the applied voltage. The different switching processes are identified using a polarizing microscope while different voltages are applied to the sample. For a small measuring voltage (less than $0.3 \mathrm{~V})$ there exists only one relaxation process with a single relaxation time. This process obeys the following equation: ${ }^{9)}$

$$
\gamma_{\varphi} \sin \theta \frac{\partial \varphi}{\partial t}=K_{\varphi} \sin ^{2} \theta \frac{\partial^{2} \varphi}{\partial x^{2}}+P_{s} E(t) \sin \varphi .
$$

which is due to the distribution of the azimuthal angle $(\varphi)$, along the $X$-axis ( $X$-mode), caused by anchoring at both the surfaces and the chevron interface. This behaviour is in contrast to that in the helical cells where $\varphi$

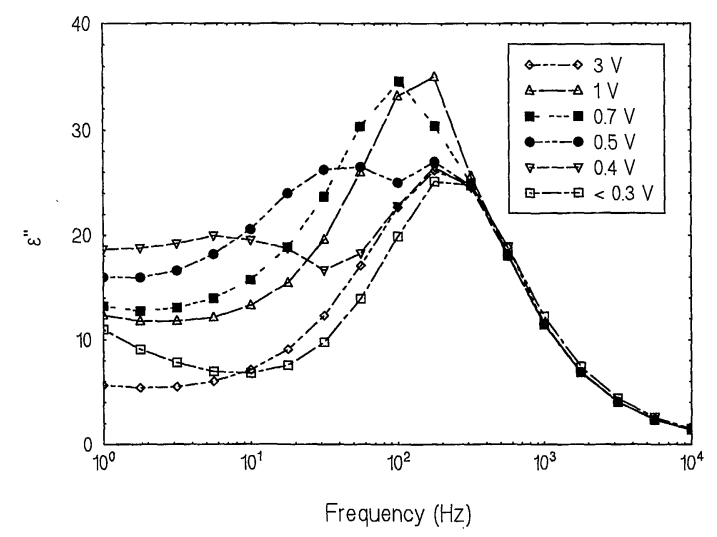

Fig. 1. Frequency dependence of the dielectric loss for different applied voltages for cell with chevron structure (SCE $13 d=7 \mu \mathrm{m}$ ).
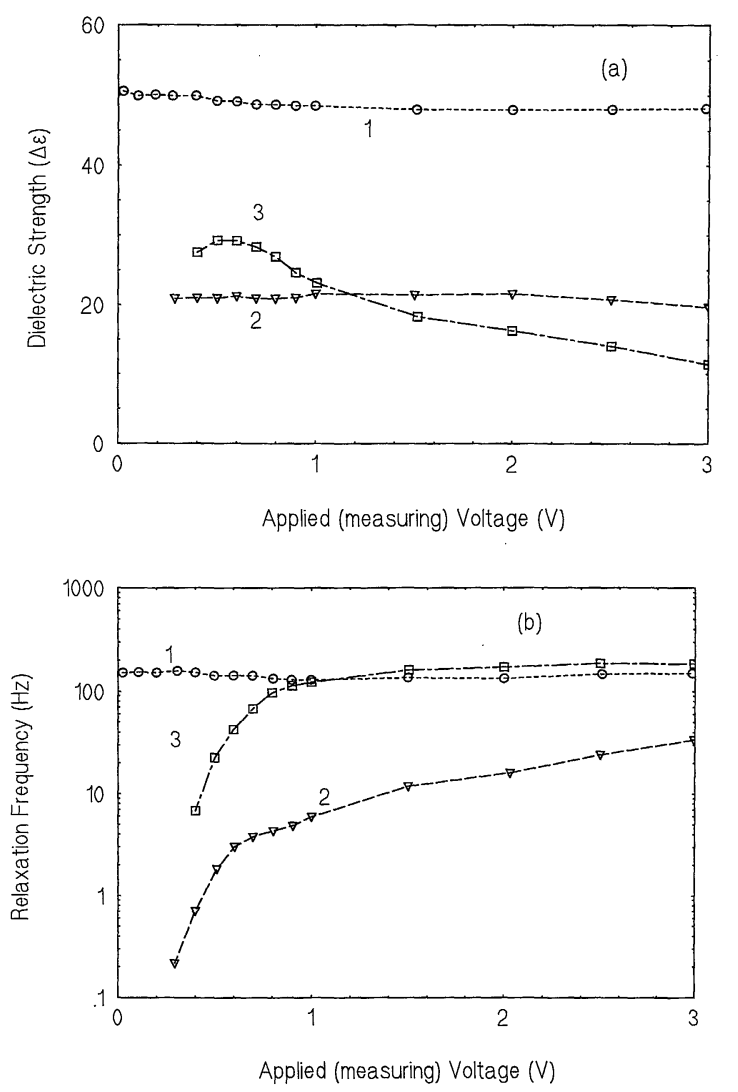

Fig. 2. Dependence of (a) the dielectric strength and (b) the relaxation frequency on applied voltage $(V)$ for cell with chevron structure (SCE13 $d=7 \mu \mathrm{m}$ ); modes 1,2 and 3 are $X$, DSL and DRP, respectively.

is distributed along the $Z$-axis ( $Z$-mode) and obeys eq. (2). For a larger value of the voltage $(0.4 \mathrm{~V})$ however, a second relaxation process is seen but the texture remains unaltered. For a still higher value of the measuring voltage $(0.5 \mathrm{~V})$ some areas of the cell exhibit switching through the domain reversed process (DRP) (mode 3 ). As seen from Fig. 2 the second and third modes are strongly non-linear in behaviour and disappear after the application of a bias voltage. The nature of the second process is still quite unclear. In agreement with X-ray investigations ${ }^{10,11)}$ there is a deformation of the smectic layer (DSL) structure under the application of even a small electric field. The characteristic time of the second relaxation process is found to be of the order of a few hundred milliseconds (Fig. 2(b)) which is approximately the same as that reported by Isogai et $a l .^{10)}$ for deformation of the smectic layers (DSL) occurring in the chevron cell. Some investigations ${ }^{12)}$ however show that the smectic layer deformation does not occur. We find that the SSFLC cells with chevron structure do show up to three relaxation processes: $X$-mode, DRP and another mode according to our interpretation is the DSL mode.

\subsubsection{Dielectric response of a SSFLC cell with book- shelf structure}

The application of a high electric field to the SSFLC cell causes an irreversible change of the smectic layer structure from chevron to the bookshelf structure. Cells possessing the bookshelf structure demonstrate a different dielectric behaviour to those with the chevron 
structure. Figure 3 shows the dielectric loss spectrum for different amplitudes of applied voltage. The dependence of the parameters of these processes $(\Delta \varepsilon$ and $f$ ) on the applied voltage is given in Figs. 4(a) and 4(b) for a cell possessing the bookshelf structure. The first process (No. 1, Fig. 4) is almost independent of the measuring parameters and possesses the same relaxation time as that of the linear process (No. 1, Fig. 2) in the chevron cell before high-field treatment. The dielectric strength of this process in the bookshelf cell is 5 to 6 times lower than for the chevron cell (Figs. 2 and 4). From the following simple consideration we show that the static susceptibility is proportional to the azimuthal pretilt angle $\left(\varphi_{0}\right)$ :

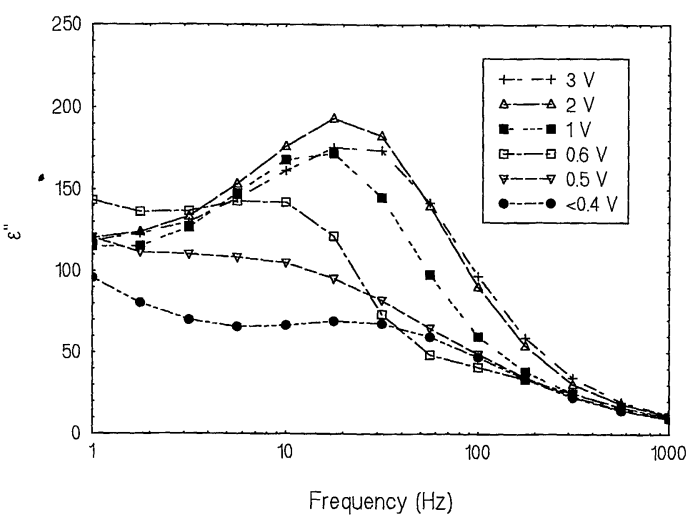

Fig. 3. Frequency dependence of the dielectric loss for different applied voltages for cell with bookshelf structure (SCE13 $d=7 \mu \mathrm{m}$ ).
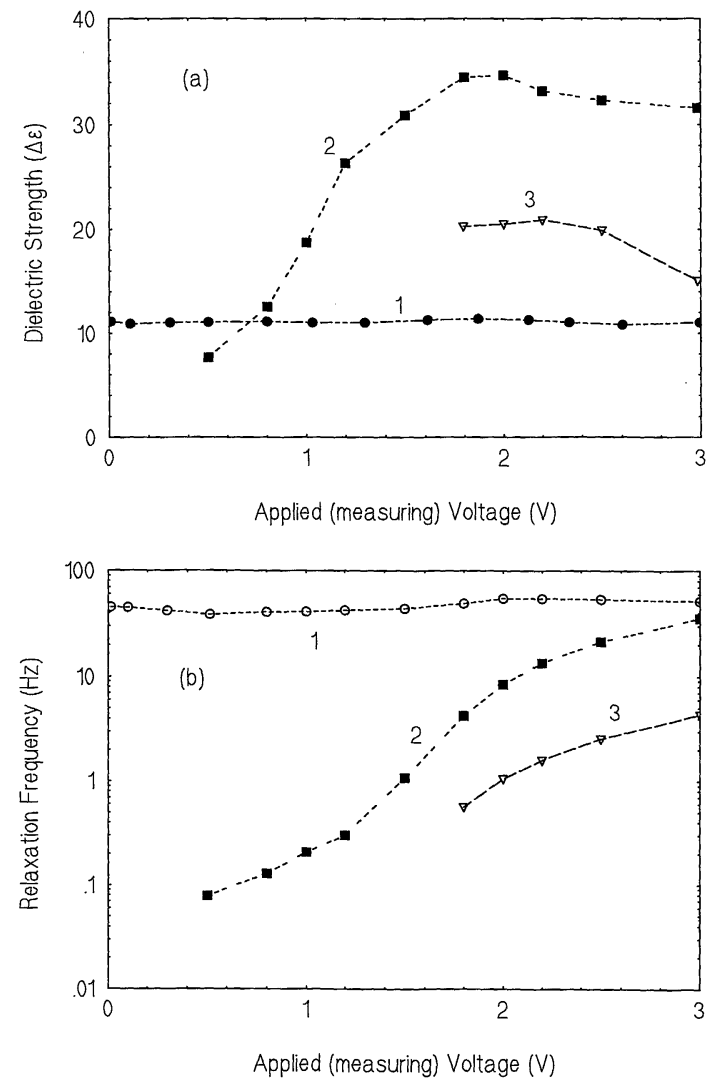

Fig. 4. Dependence of (a) the dielectric strength and (b) the relaxation frequency on applied voltage $(V)$ for cell with bookshelf structure (SCE13 $d=7 \mu \mathrm{m}$ ); mode $1-X$ mode; 2 and 3 -not classified (probably domain walls motion).

$$
\chi=\frac{\partial\langle P\rangle}{\partial E}=P_{\mathrm{s}} \lim _{\Delta E \rightarrow 0}\left(\frac{\cos \varphi_{0}-\cos \varphi}{\Delta E}\right)=P_{\mathrm{s}} \sin \varphi_{0} \frac{\partial \varphi}{\partial E} .
$$

It is known that the azimuthal pretilt angle at the surface in a chevron cell $\left(\sim 60^{\circ}\right)$ is larger than that in the bookshelf structure $\left(10-15^{\circ}\right)$ and this leads to a difference in the static dielectric permittivity. The second process (No. 2) appearing in the middle frequency range corresponds to the domain wall motion between two different ("up" and "down") uniform domains. ${ }^{13)}$ The latter two processes are found to be non-linear (Figs. 4(a) and 4(b)) (i.e. $\Delta \varepsilon$ and $f$ are dependent on the electric field).

\section{Conclusions}

The experiments performed on three FLC-mixtures with different values of the helix pitch indicate complex dielectric behaviour in the frequency range $0.1 \mathrm{~Hz}-$ $100 \mathrm{kHz}$. Up to four different processes could be simultaneously present in a FLC cell as determined from its dielectric response. All these processes deal with the director motion about the azimuthal angle $(\varphi)$ with constant tilt $(\theta)$ and therefore may correspond to the Goldstone mode. It was shown that short-helix-pitch FLC cells possess only one Debye relaxation process. However for SSFLC cells the dielectric response is much more complicated and depends on the applied alternating voltage and the smectic layer packing in the cell. Using a combination of dielectric spectroscopy and optical studies of cell textures, we are able to distinguish the relaxation processes and assign these to the helix distortion mode ( $Z$-mode), azimuthal pretilt angle distortion ( $X$-mode), DRP-domain reversed process, and another process the nature of which is still unclear but is perhaps due to the distortion of the smectic layer (DSL) structure.

We thank Professor B. K. P. Scaife and Dr. Yu. P. Kalmykov for useful discussions.

1) A. Levstik, T. Carlsson, C. Filipič, I. Levstik and B. Žekš: Phys. Rev. Lett. 35 (1987) 3527.

2) P. G. Costello, Yu. P. Kalmykov and J. K. Vij: Phys. Rev. A 46 (1992) 4856

3) F. Gouda, K. Skarp and S. T. Lagerwall: Ferroelectrics 113 (1991) 165.

4) J. Pavel, M. Glogarova and S. S. Bawa: Ferroelectrics 67 (1987) 221.

5) R. J. Cava, J. S. Patel, K. R. Collen, J. W. Goodby and E. A. Rietman: Phys. Rev. A 35 (1987) 4378.

6) J. Zubia, A. Ezcurra, M. R. De La Fuenta and M. A. Perez Jubindo: Liq. Cryst. 10 (1991) 849.

7) V. M. Vaksman, Yu. P. Panarin: Mol. Mater 1 (1992) 147.

8) S. Havriliak and S. Negami: J. Polym. Sci. C 14 (1966) 99.

9) N. A. Clark, M. A. Handschy and S. T. Lagerwall: Mol. Cryst. Liq. Cryst. 94 (1983) 213.

10) M. Isogai, M. Oh-E, T. Kitamura and A. Mikoh: Mol. Cryst. Liq. Cryst. 207 (1991) 87.

11) M. Oh-E, M. Isogai and T. Kitamura: Liq. Cryst. 11 (1992) 101.

12) P. C. Willis, N. A. Clark and C. R. Safinya: Liq. Cryst. 11 (1992) 581.

13) A. Fukuda, Yu. Ouchi, H. Arai, H. Takano, S. Ishikawa and H. Takezoe: Liq. Cryst 5 (1989) 1055. 